Article

\title{
Purification and Characterization of Two Novel Laccases from Peniophora lycii
}

\author{
Olga A. Glazunova *, Konstantin V. Moiseenko, Olga S. Savinova and Tatyana V. Fedorova *
}

A.N. Bach Institute of Biochemistry, Research Center of Biotechnology of the Russian Academy of Sciences, 119071 Moscow, Russia; mr.moiseenko@gmail.com (K.V.M.); savinova_os@rambler.ru (O.S.S.)

* Correspondence: olga.a.glas@gmail.com (O.A.G.); fedorova_tv@mail.ru (T.V.F.)

Received: 16 November 2020; Accepted: 3 December 2020; Published: 6 December 2020

\begin{abstract}
Although, currently, more than 100 laccases have been purified from basidiomycete fungi, the majority of these laccases were obtained from fungi of the Polyporales order, and only scarce data are available about the laccases from other fungi. In this article, laccase production by the white-rot basidiomycete fungus Peniophora lycii, belonging to the Russulales order, was investigated. It was shown that, under copper induction, this fungus secreted three different laccase isozymes. Two laccase isozymes-Lac5 and LacA-were purified and their corresponding nucleotide sequences were determined. Both purified laccases were relatively thermostable with periods of half-life at $70^{\circ} \mathrm{C}$ of 10 and $8 \mathrm{~min}$ for Lac5 and LacA, respectively. The laccases demonstrated the highest activity toward ABTS (97 U.mg ${ }^{-1}$ for Lac5 and $121 \mathrm{U} \cdot \mathrm{mg}^{-1}$ for LacA at pH 4.5); Lac5 demonstrated the lowest activity toward 2,6-DMP (2.5 U.mg ${ }^{-1}$ at $\left.\mathrm{pH} 4.5\right)$, while LacA demonstrated this towards gallic acid (1.4 U.mg ${ }^{-1}$ at $\left.\mathrm{pH} 4.5\right)$. Both Lac5 and LacA were able to efficiently decolorize such dyes as RBBR and Bromcresol Green. Additionally, phylogenetic relationships among laccases of Peniophora spp. were reconstructed, and groups of orthologous genes were determined. Based on these groups, all currently available data about laccases of Peniophora spp. were systematized.
\end{abstract}

Keywords: laccase; Peniophora lycii; substrate specificity; dye decolorization

\section{Introduction}

Fungi that cause white rot of wood (i.e., white-rotting fungi or white-rot fungi) are a unique group of decomposers that can degrade all components of plant cell walls, including such a difficultly degradable biopolymers as lignin. In nature, these fungi play a fundamental role in carbon balance, soil formation, and forest regeneration [1,2]. Almost all white-rot fungi belong to the Basidiomycota division; ascomycetes of the genus Xylaria are an exception. In the process of growth and development, white-rot fungi produce a vast array of extracellular enzymes, one of which-laccase-has been attracting the attention of researchers for more than 100 years [3].

Laccase (benzenediol:oxygen oxidoreductase, EC 1.10.3.2) is a multi-copper oxidase that can perform one-electron oxidation of different substrates with a concomitant reduction of molecular oxygen to water [4]. As an oxidizing substrate, laccases can utilize substituted phenols, aromatic amines, and a number of other complex aromatic compounds containing hydroxyl or amino groups [5]. Due to their broad substrate specificity, laccases can be potentially used in a wide variety of technical applications, including pulp and paper and textile industries, production of biosensors, wastewater treatment, and soil bioremediation [6-8].

Although laccase is an enzyme with more than 100 years' history of exploration, its exact biological function is still debatable. Originally, laccase was considered as a lignin-degrading enzyme, but later this view was reassessed [9]. Over the past decades, several biological functions were proposed for laccases including morphogenesis, fungal plant-pathogen/host interaction, stress defense, pigment formation, 
and detoxification of phenolic compounds $[10,11]$. Additionally, it was speculated that in different fungi, laccases can perform different functions; however, current genomic data had demonstrated that the situation is more complicated. Based on the extensive sequencing, performed under the 1000 Fungal Genomes Project [12], it was demonstrated that laccase genes in basidiomycete genomes always form multigene families comprised of many non-allelic (paralogous, serially duplicated) genes. Consequently, each fungus can produce many laccase isozymes (i.e., products of different non-allelic genes) that can perform different functions. From the above, it is apparent that only systematic comparisons of laccases from different fungi, as well as comparisons of laccase isozymes from the same fungus, can potentially shed light on the range of biological functions of laccases. In addition, the more naturally occurring variations in laccase are discovered, the better rational design of this enzyme can be performed for biotechnology.

The majority of currently characterized laccases were obtained from fungi of the Polyporales order. Recently, evolutionary relationships among these laccases were reconstructed, and their orthology-based classification was proposed [13]. At least for the Core Polyporoid clade of Polyporales, this classification was proven to be useful for bringing order to the very scattered data regarding different laccase isozymes from different fungi. Additionally, information about the orthology relationships between genes allows invoking so-called "orthology conjecture"-i.e., potential extrapolation of known properties of isozymes onto their orthologs [14-16]. In contrast to the laccases from fungi of the Polyporales order, less is known about laccases from fungi of the Agaricales order, and almost nothing is known about laccases from other Basidiomycetes.

Here, we present a study of laccases from Peniophora lycii (Pers.) Hoehn. \& Litsch. belonging to the Peniophoraceae family of the Russulales order. The Russulales are one of the recently elucidated lineages in the homobasidiomycetes [17]. This order is very morphologically diverse and contains saprotrophic, ectomycorrhizal, root-parasitic, and insect-symbiotic fungi. Within this order, Peniophoraceae form a well-supported clade containing primarily saprotrophic fungi. P. lycii is a resupinate lichen-like species that usually colonizes dead branches of deciduous and coniferous trees all over the world.

Currently, only 11 published articles can be found about laccases from fungi of the Peniophora genus [18-28]. Worse than that, almost all these works are strictly technically oriented and use only crude laccase preparations: only in three works $[20,22,28]$ laccases were purified; only in four works $[20,21,25,26]$ used fungi were identified to the species level; only in two works [21,29] fungi were properly genetically barcoded; and only in three works $[25,28,29]$ either full or partial sequences of used laccases were obtained. This situation enormously complicates any comparative studies and raises serious reproducibility issues. Additionally, although currently three genomes of Peniophora spp. are available, no phylogenetic study of their laccases has been performed.

In this article, two laccases isozymes of $P$. lycii LE-BIN 2142 were isolated and characterized. Further, using available genome sequences of Peniophora spp., phylogenetic relationships among their laccases were reconstructed and orthology groups were determined. These groups were further used for systematization of the available data about laccases of Peniophora spp. and as a guide for the determination of sequences for the isolated laccases of P. lycii LE-BIN 2142.

\section{Materials and Methods}

\subsection{Fungal Strain and Culture Conditions}

The fungal strain Peniophora lycii LE-BIN 2142 was obtained from the Komarov Botanical Institute Basidiomycetes Culture Collection (LE-BIN; St. Petersburg, Russia). The sequence of its ITS1-5.8S rRNA-ITS2 region is available at the NCBI GenBank accession JX046435. In the laboratory, the fungal mycelium was stored on wort-agar slants at $4{ }^{\circ} \mathrm{C}$.

To obtain the starting inoculum, the fungus was cultivated in $750 \mathrm{~mL}$ Erlenmeyer flasks with $200 \mathrm{~mL}$ of glucose-peptone (GP) medium (per $1 \mathrm{~L}$ of $\mathrm{dH}_{2} \mathrm{O}$ ): $3.0 \mathrm{~g}$ peptone, $10.0 \mathrm{~g}$ glucose, $0.6 \mathrm{~g}$ $\mathrm{KH}_{2} \mathrm{PO}_{4}, 0.4 \mathrm{~g} \mathrm{~K}_{2} \mathrm{HPO}_{4} \times 3 \mathrm{H}_{2} \mathrm{O}, 0.5 \mathrm{~g} \mathrm{MgSO}_{4} \times 7 \mathrm{H}_{2} \mathrm{O}, 0.5 \mathrm{~g} \mathrm{CaCl}_{2}, 50 \mathrm{mg} \mathrm{MnSO}_{4} \times 5 \mathrm{H}_{2} \mathrm{O}, 1 \mathrm{mg} \mathrm{ZnSO}_{4}$, 
and $0.5 \mathrm{mg} \mathrm{FeSO}_{4}$. The cultivation was carried out statically for $15-18$ days in the dark at $26-28{ }^{\circ} \mathrm{C}$. The inoculum was obtained by disruption of the mycelium with ceramic beads; all inoculations were performed with $25 \mathrm{~mL}$ of disrupted mycelium.

For optimization of laccase production, four different media were used. Medium A had the same composition as the GP medium with an addition of $0.15 \mathrm{~g} \cdot \mathrm{L}^{-1}$ of $\mathrm{CuSO}_{4} \times 5 \mathrm{H}_{2} \mathrm{O}$. Medium C was different from medium A only in the concentrations of peptone $\left(1 \mathrm{~g} \cdot \mathrm{L}^{-1}\right)$ and glucose $\left(20 \mathrm{~g} \cdot \mathrm{L}^{-1}\right)$. Medium B and medium D had the same compositions as medium A and medium C, respectively, but peptone was substituted with tryptone.

All cultivations were performed in $750 \mathrm{~mL}$ Erlenmeyer flasks containing $200 \mathrm{~mL}$ of the corresponding medium. The fungus was cultivated by the submerged method on a circular shaker (180 RPM) at $27^{\circ} \mathrm{C}$ for 21 days in the dark.

Laccase activity was measured spectrophotometrically using a Lambda 35 spectrophotometer (PerkinElmer, Waltham, MA, USA) with $10 \mathrm{mM}$ catechol (Sigma, St. Louis, MO, USA) as a substrate $\left(\varepsilon_{410}=740 \mathrm{~cm}^{-1} \cdot \mathrm{M}^{-1}\right)$ in $0.1 \mathrm{M} \mathrm{Na}$-acetate buffer $\mathrm{pH} 4.5$.

\subsection{Purification of Laccases}

For laccase purification, the protocol described in [30] was modified. All procedures were performed at $4{ }^{\circ} \mathrm{C}$. Culture filtrate $(6400 \mathrm{~mL})$ was $90 \%$ saturated with $\left(\mathrm{NH}_{4}\right)_{2} \mathrm{SO}_{4}$, and the precipitate was separated by filtration (Whatman No. 1 filter paper), re-suspended in $\mathrm{dH}_{2} \mathrm{O}$, and dialyzed against $\mathrm{dH}_{2} \mathrm{O}$ overnight. At the next stage, the preparation was stirred with DEAE-cellulose for $20 \mathrm{~min}$, and the proteins were desorbed twice with $200 \mathrm{mM}$ potassium phosphate buffer (KPB) $\mathrm{pH}$ 6.5. The resulting preparation was dialyzed against $5 \mathrm{mM} \mathrm{KPB} \mathrm{pH} 6.5$ and loaded on a column packed with $25 \mathrm{~mL}$ of DEAE-Toyopearl 650M (Tosoh, Tokyo, Japan) and equilibrated with $5 \mathrm{mM} \mathrm{KPB} \mathrm{pH} \mathrm{6.5.} \mathrm{Proteins}$ were eluted by $150 \mathrm{~mL}$ of $50 \mathrm{mM} \mathrm{KPB} \mathrm{pH} \mathrm{6.5.} \mathrm{For} \mathrm{further} \mathrm{purification,} \mathrm{fractions} \mathrm{with} \mathrm{laccase} \mathrm{activity}$ were dialyzed against $20 \mathrm{mM} \mathrm{KPB} \mathrm{pH} 6.5$ and subjected to FPLC size-exclusion chromatography on a Superdex 75 (26/60) column (GE Healthcare Life Sciences, Chicago, IL, USA) equilibrated with $20 \mathrm{mM}$ $\mathrm{KPB} \mathrm{pH}$ 6.5. Fractions with different laccase izoenzymes were transferred to $5 \mathrm{mM}$ citrate-phosphate buffer $\mathrm{pH} 5.0$ by dialysis and purified by an additional stage of ion-exchange chromatography on a DEAE-Toyopearl 650M column equilibrated with $5 \mathrm{mM}$ citrate-phosphate buffer $\mathrm{pH}$ 5.0. Proteins were eluted by a linear gradient of $5-20 \mathrm{mM}$ of the same buffer.

\subsection{Gel Electrophoreses, Isoelectric Focusing, and MALDI-TOF/TOF MS Identification}

The SDS-PAGE was performed according to Laemmli [31] in a Mini-PROTEAN 3 device (Bio-Rad, Hercules, CA, USA). Protein bands were stained with Coomassie Brilliant Blue R-250 (Sigma, St. Louis, MO, USA). The PageRuler Prestained Protein Ladder (Thermo Fisher Scientific, Waltham, MA, USA) with a range of $10-200 \mathrm{kDa}$ was used as a standard.

The analytical isoelectric focusing on polyacrylamide gel (IEF-PAGE) was carried out using Servalyte 3-5 ampholytes (Serva, Heidelberg, Germany) on a Mini IEF Cell (Bio-Rad, Hercules, CA, USA). Protein bands were stained with Coomassie Brilliant Blue R-250 (Sigma, St. Louis, MO, USA). The protein mixture from the Amersham IEF Calibration Kit Low-Range pI (pH 2.5-6.5) (GE Healthcare UK, Amersham, UK) was used as a standard.

Two-dimensional gel electrophoresis (2D-GE) was performed on a Protean II xi 2-D Cell system (Bio-Rad, Hercules, CA, USA). The isoelectric focusing was carried out using Servalyte 3-10 ampholytes (Serva, Heidelberg, Germany), and the subsequent electrophoresis was performed in a gradient SDS polyacrylamide gel (7.5-25\%). The visualization of proteins was performed with $\mathrm{AgNO}_{3}$ staining.

For the MALDI-TOF/TOF MS identification, the proteins were seized from the gel and digested with the trypsin. The obtained peptides were spotted on a MALDI target plate and analyzed by MALDI-TOF/TOF spectrometry on a Ultraflex II MALDI-TOF/TOF mass spectrometer (Bruker Daltonics, Bremen, Germany) equipped with a UV laser (Nd) in a positive ion regimen with a reflectron for peptide fingerprinting. The fragmentation spectra were obtained using a tandem regimen of the 
device, and the accuracy of measurement of fragmented ions was no less than $1 \mathrm{Da}$. The mass spectra were processed using the FlexAnalysis 3.3 program (Bruker Daltonics, Bremen, Germany). The search for proteins corresponding to MALDI-TOF/TOF MS data was carried out with Mascot Peptide Mass Fingerprint in the fungal subset of NCBI non-redundant protein sequences, taking into account possible oxidation of methionine and modification of cysteine residues. The search with combined data of the peptide masses and peptide fragmentation was performed with Biotools 3.2 (Bruker Daltonics, Bremen, Germany). Additionally, sequences of the peptides individually derived from the fragmentation data were analyzed by an in-house database of Peniophora spp. laccases (see "Phylogenetic Analysis" section) or BLAST NCBI using the fungal subset of the GenBank. For identification of the occupied glycosylation sites, laccase samples were treated with Endo H (Sigma, St. Louis, MO, USA) and subjected to MALDI-TOF/TOF MS/MS, as was previously described in [32].

\subsection{Laccase Characterization}

The UV-visible absorption spectra of the laccases $\left(1.0 \mathrm{mg} \cdot \mathrm{mL}^{-1}\right)$ in $50 \mathrm{mM}$ potassium phosphate buffer $\mathrm{pH} 6.5$ were recorded with a Lambda 35 spectrophotometer (PerkinElmer, Waltham, MA, USA) in a $1 \mathrm{~cm}$ quartz cell at $25^{\circ} \mathrm{C}$ in the range of $200-800 \mathrm{~nm}$.

For the Azure B assay [33], $10 \mu \mathrm{L}$ of the enzyme sample with a concentration of $0.1 \mathrm{mg} \cdot \mathrm{mL}^{-1}$ was added to the reaction mixture consisting of $900 \mu \mathrm{L}$ of $0.02 \%$ Azure B (AppliChem, Darmstadt, Germany) dissolved in $0.1 \mathrm{M}$ sodium acetate buffer $\mathrm{pH} 4.5$ and $100 \mu \mathrm{L}$ of $10 \mathrm{mM}$ hydroxybenzotriazole (HOBt, Sigma, St. Louis, MO, USA). The reaction was carried out at $25^{\circ} \mathrm{C}$ for $24 \mathrm{~h}$. Laccases from Trametes hirsuta, Antrodiella faginea, and Steccherinum murashkinskyi obtained in previous studies were used as control enzymes with known redox potential [33,34].

The effect of $\mathrm{pH}$ on the laccase activity was studied by measuring the enzyme activity in citrate-phosphate buffers ( $\mathrm{pH}$ 2.6-6.5). Measurements were performed using the following substrate concentrations: $0.1 \mathrm{mM}$ for sinapic and ferulic acids; $1 \mathrm{mM}$ for ABTS, gallic acid, and 2,6-DMP; $5 \mathrm{mM}$ for guaiacol; and $10 \mathrm{mM}$ for catechol. The molar extinction coefficients were $740 \mathrm{~cm}^{-1} \cdot \mathrm{M}^{-1}$ at $410 \mathrm{~nm}$ for catechol [35], 29,500 $\mathrm{cm}^{-1} \cdot \mathrm{M}^{-1}$ at $436 \mathrm{~nm}$ for ABTS [13], 35,645 $\mathrm{cm}^{-1} \cdot \mathrm{M}^{-1}$ at $470 \mathrm{~nm}$ for 2,6-DMP [36], 26,600 $\mathrm{cm}^{-1} \cdot \mathrm{M}^{-1}$ at $470 \mathrm{~nm}$ for guaiacol [37], $4610 \mathrm{~cm}^{-1} \cdot \mathrm{M}^{-1}$ at $385 \mathrm{~nm}$ for gallic acid [38], $14,640 \mathrm{~cm}^{-1} \cdot \mathrm{M}^{-1}$ at $306 \mathrm{~nm}$ for sinapic acid [39], and $12,940 \mathrm{~cm}^{-1} \cdot \mathrm{M}^{-1}$ at $314 \mathrm{~nm}$ for ferulic acid [33]. All measurements were performed in triplicate.

Thermostability of laccases was measured after pre-incubation of the enzyme samples $\left(0.1 \mathrm{mg} \cdot \mathrm{mL}^{-1}\right)$ in $50 \mathrm{mM} \mathrm{KPB} \mathrm{pH} 6.5$ at $70{ }^{\circ} \mathrm{C}$, and residual activity was assayed with ABTS as a substrate.

For the dye decolorization capacity assay, Remazol Brilliant Blue R (RBBR), Bromocresol Green (BCG), Phenol Red (PR), Reactive Black 5 (RB5), Indigo Carmine (IC), and Congo Red (CR) were dissolved in water in a concentration of $1 \mathrm{mM}$. The reaction mixture contained $100 \mu \mathrm{L}$ of dye solution, $1900 \mu \mathrm{L}$ of buffer, and $10 \mu \mathrm{L}$ of laccase solution with a concentration of $1 \mathrm{mg} \cdot \mathrm{mL}^{-1}$. Sodium acetate buffer $\mathrm{pH} 4.5$ was used for all dyes with the exception of CR. For the CR acetate buffer, pH 5.5 was used as this compound can change the color in the $\mathrm{pH}$ range of 3.5-5.2. Absorbance spectra were recorded before addition of the enzyme and after 2 and $24 \mathrm{~h}$ of incubation at $25^{\circ} \mathrm{C}$. The degree of dye decolorization was calculated as the relative difference in absorbance at characteristic wavelengths: $595 \mathrm{~nm}$ for RBBR and RB5, $615 \mathrm{~nm}$ for BCG, $430 \mathrm{~nm}$ for PR, $610 \mathrm{~nm}$ for IC, and $490 \mathrm{~nm}$ for CR.

\subsection{DNA Extraction, PCR Amplification, and Sequencing}

For DNA extraction, the fungal mycelium was ground in liquid nitrogen, and total DNA was extracted using the DNeasy Plant Mini Kit (Qiagen, Hilden, Germany), according to the manufacturer's instructions.

To amplify the lac5 gene, the following primers were used: F1 (5'-GCGTCTCTCTTTC ACGTTAC- $\left.3^{\prime}\right)$, and R1 (5'-TTAAAGAGAGTTGGGATTGGC-3'). These primers were designed based on the alignment of the nucleotide sequences of the laccases from the 5th orthology group 
(see Section 3.1). The amplification was performed with the Taq PCR kit (Evrogen, Moscow, Russia) and included: 1 cycle of $3 \mathrm{~min}$ at $95^{\circ} \mathrm{C} ; 30$ cycles of $\left(30 \mathrm{~s}\right.$ at $95^{\circ} \mathrm{C}, 30 \mathrm{~s}$ at $55{ }^{\circ} \mathrm{C}$, and $150 \mathrm{~s}$ at $72{ }^{\circ} \mathrm{C}$ ); and 1 cycle of $5 \mathrm{~min}$ at $72{ }^{\circ} \mathrm{C}$. Obtained PCR products of $\sim 2300 \mathrm{bp}$ were purified from the agarose gel by the QIAquick Gel Extraction Kit (Qiagen, Hilden, Germany) and sequenced by the standard Sanger sequencing method. The amplification primers were used at the first round of sequencing. The second round of sequencing was performed with the following primers: F2 (5'-CTAGGCACTACAAGACTCA-3'), and R2 (5'-TGCCGATAGATACCACATC-3'), designed based on the sequences obtained in the first round. All four obtained sequences were manually assembled. The exon-intron structure was predicted using Augustus software [40] and manually curated by alignment with known laccases [13]. The annotated consensus sequence was deposited into GenBank under the accession number MW172826.

\subsection{Phylogenetic Analysis}

To collect laccase sequences, the genomes of Peniophora sp. CONTA v1.0 and Peniophora sp. v1.0 were extracted from the JGI (Joint Genome Institute) portal [41], and the genome of Peniophora sp. CBMAI was extracted from the GeneBank database [42]. The search for laccase genes was performed using both existing functional annotations and a BLAST [43] search against known laccases [13]. As a result, 53 non-redundant laccase sequences were obtained. Since, in all genomes, protein identifiers and names of gene models are in one-to-one relationships, in the following, text protein identifiers, as the most concise, were chosen to refer to the obtained genes.

For the phylogenetic analysis, codon-based multiple sequence alignment of protein-coding sequences (CDS) was generated using the MUSCLE algorithm (File S1) [44,45]. The ambiguous alignment regions were removed with the guidance of the Gblocks (v 0.91b) program (File S2) [46]. The best fitting model of the sequence evolution was determined using jModelTest2 software [47] with 11 substitution schemes. The model selection was computed using the Akaike information criterion (AIC), and the GTR+GAMMA model was selected. The phylogenetic tree was constructed under the maximum likelihood criterion (ML) with the RAxML-HPC BlackBox (v 8.2.10) program [48] at the CIPRES Science Gateway [49]. The reliability for the internal nodes was assessed using the bootstrapping method (1000 bootstrap replicates).

\subsection{Bioinformatics and Visualization}

SignalP 5.0 Server was used to predict the signal peptide [50]. The glycosylation sites were predicted with NetNGlyc 1.0 (http://www.cbs.dtu.dk/services/NetNGlyc/) [51]. The SWISS-MODEL server was used for homology modeling of the laccase structures [52]. CCP4MG [53] was used to construct ribbon diagrams of $\mathrm{T} 1$ centers of laccases.

\section{Results and Discussion}

\subsection{Orthology Groups of Laccases from Fungi of Peniophora Genus}

Since no published information is available about the laccase multigene family in fungi of the Peniophora genus, at the first stage of our investigation, a search of laccase genes in the publicly available genomes of these fungi was performed. As a result of this search, it was demonstrated that fungi of the Peniophora genus possess from 15 to 19 non-allelic laccase genes (Figure 1). Almost all found laccase genes were located on different contigs. The exception was ProtID 613815 and ProtID 665656 from Peniophora sp. CONTA and ProtID 684578 and ProtID 734113 from Peniophora sp. v1.0. This suggests that in the genomes of Peniophora spp., almost all laccase genes either locate on different chromosomes of the fungi or on the same chromosome at a significant distance from each other. 


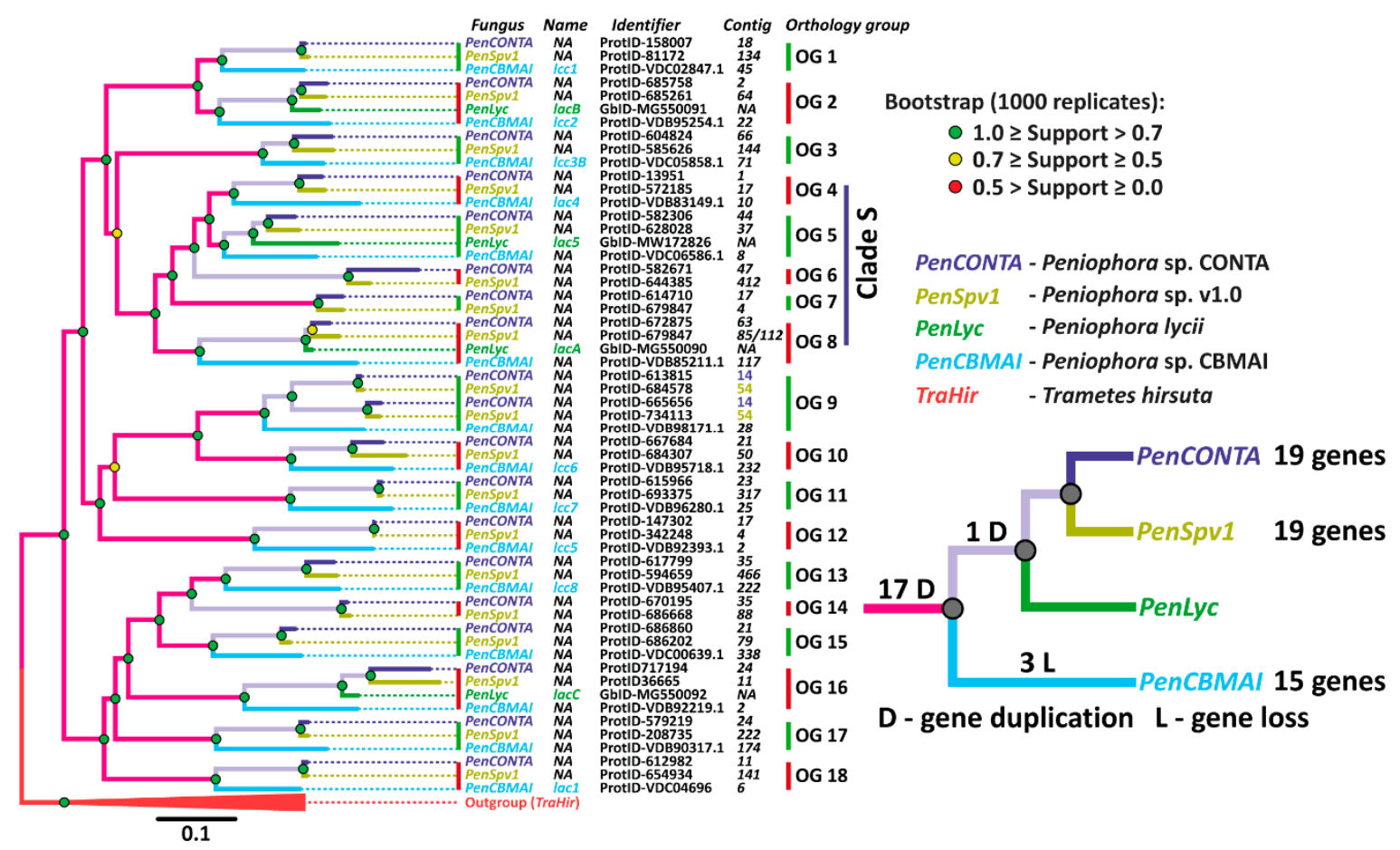

Figure 1. The phylogenetic relationships among laccases of Peniophora spp. The clades which form orthology groups are designated as OG. The clade containing laccases secreted by P. lycii (Lac5, Lac7, LacA) is designated as Clade S. For the laccases obtained from sequenced genomes, protein IDs (ProtID) are used as gene identifiers, while for other laccases, GenBank accession number (GbID) are provided.

On the phylogenetic tree (Figure 1), the laccase genes of Peniophora spp. form 18 clades containing one gene from each fungus. The exceptions are clades 6, 7, and 14 lacking the gene from Peniophora sp. CBMAI, and clade 9 containing two genes from Peniophora sp. CONTA and Peniophora sp. v1.0. For further discussion, both sequences of $P$. lycii laccases previously obtained by us-lacA, lacB, and lacC $[13,54]$ —and the sequence obtained in the current study-lac5-were placed on the tree.

The topology of the phylogenetic tree indicates that the process of duplication of the ancestral laccase gene began before the splitting of the evolutionary branch leading to fungi of the Peniophora genus into different species. Moreover, after the division into species, both gene duplications and losses were rare events. The loss of laccase genes is observed only in the evolutionary line leading to Peniophora sp. CBMAI (clades 6, 7, and 14), and duplication occurs only in the closest common ancestor for Peniophora sp. CONTA and Peniophora sp. v1.0 (clade 9). It should be noted that a similar picture of the evolution of laccase genes-early multiple duplication with subsequent retention of an almost unchanged number of genes-was also described for fungi from the Core and Residual Polyporoid clades of the Polyporales order [13,55-57]. Similar to the Polyporales order, since almost all detected gene duplications occurred in the common ancestor of all Peniophora spp., all 18 clades on the constructed tree can be regarded as well-defined orthology groups.

Currently, only for Peniophora sp. CBMAI data about the genome, transcriptome, secretome, and the main secreted laccase are available $[19,22,29,58]$. Based on the transcriptomic data, it was previously shown that Peniophora sp. CBMAI expressed at least nine laccase genes-lcc1-8 and lac1 $[29,58]$. However, the exoproteomic study demonstrated secretion of the only one laccase isozyme-Lac1 [29], which belongs to the 18th orthology group. This isozyme was purified and characterized in [22]. A reciprocal BLAST search with previously reported partial sequences of laccases from Peniophora sp. VTT D-00815 [28] and Peniophora incarnata KUC8836 (pilc1) [25] allowed us to unambiguously assign them to the 5 th and 15 th orthology groups, respectively. 


\subsection{Culture Conditions, Purification, Identification, and Characterization of Laccases}

As the level of laccase activity in fungi is largely determined by the cultivation conditions, four variants of culture media were tested for laccase production. In all the media, $\mathrm{CuSO}_{4}$ was used as a laccase inductor. The media were different in the type and concentration of the nitrogen source and the concentration of glucose (primary carbon source): medium A contained $0.3 \%$ of peptone and $1 \%$ of glucose; medium $\mathrm{B}-0.3 \%$ of tryptone and $1 \%$ of glucose; medium $\mathrm{C}-0.1 \%$ of peptone and $2 \%$ of glucose; and medium $\mathrm{D}-0.1 \%$ of tryptone and $2 \%$ of glucose.

In choosing these media, the following rationales were used: (1) $\mathrm{CuSO}_{4}$ is a well-known, most widely used, and almost universal inductor of laccase production in fungi [5]. (2) Although the peptone-containing media are widely used for laccase production, according to the previously published data for Peniophora sp. NFCCI-2131, replacement of peptone with tryptone increased the laccase activity in the culture liquid by 1.7 times [27]. Additionally, for Peniophora sp. JS17, tryptone was also indicated as the optimal nitrogen source [24]. (3) Previously, it was demonstrated that the ratio of carbon to nitrogen sources in the medium may have a substantial effect on the laccase production [5].

For all four media, the activity increased monotonically throughout the entire cultivation period. By the 21st day of cultivation, it comprised $4 \mathrm{U} \cdot \mathrm{mL}^{-1}, 0.8 \mathrm{U} \cdot \mathrm{mL}^{-1}, 1.2 \mathrm{U} \cdot \mathrm{mL}^{-1}$, and $0.5 \mathrm{U} \cdot \mathrm{mL}^{-1}$ on medium A, B, C, and D, respectively. Hence, to obtain a sufficient quantity of starting material for laccase purification, the fungus was further cultivated on medium $\mathrm{A}$.

At the first stage of purification (Figure 2), proteins were precipitated with $\left(\mathrm{NH}_{4}\right)_{2} \mathrm{SO}_{4}$. Since the obtained precipitate contained a lot of pigments, the second purification stage involved batch absorption onto DEAE-cellulose. The obtained sample was desalted and concentrated. To assess the possible diversity of laccase isozymes in the sample, 2D-GE followed by MALDI-TOF/TOF MS identification was performed (Figure S1). As a result, it was shown that the sample contained three laccase isozymes (Figure 2) belonging to the fifth, seventh, and eighth orthology groups (Figure 1, Figure S1). Consequently, they were named Lac5, Lac7, and LacA. It is worth noting that for fungi of the genus Peniophora, the secretion of several laccases, differing in molecular weight and isoelectric point, was previously shown $[20,28]$. However, these studies did not establish whether the detected laccases were different isozymes (i.e., products of different genes) or isoforms (i.e., products of the same gene with different posttranslational modifications).

On the phylogenetic tree of the laccases from Peniophora spp. (Figure 1), it can be seen that the orthology groups secreted by $P$. lycii laccase isozymes are clustered together, forming Clade $S$. At the same time, among all previously reported laccases of the Peniophora genus, for which orthology groups could be determined, only laccase from Peniophora sp. VTT D-00815 (fifth orthology group) [28] belonged to this clade. The secretion of a laccase isozyme from different orthology groups by Peniophora incarnata KUC8836 (15th orthology group) [25] can be explained by the presence of Tween 80 and pyrene in the culture medium. Further, the secretion of laccase from orthology groups other than those contained in Clade S by Peniophora sp. CBMAI (18th orthology group) [29] can be a result of the very different lifestyle of this fungus, which was isolated from a coral reef in Brazil [29].

The third purification stage (Figure 2) comprised anion exchange chromatography, while the fourth stage comprised size-exclusion chromatography. Since some of the obtained fractions clearly contained two different isozymes, at the fifth stage, they were further fractionated by the second anion exchange chromatography with a different buffer system. Unfortunately, the obtainment of the pure laccase isozymes at the fifth purification stage came at a cost of diminished total specific activity and yield. As a result, two pure laccase isozymes-Lac5 and LacA-were obtained. The final amount of Lac5 (13 mg) was 1.5 times lower than that of LacA $(19 \mathrm{mg})$. The yields of Lac5 and LacA were 2.4 and $1.4 \%$, and their specific activity measured with catechol comprised 46.9 and $19.1 \mathrm{U} \cdot \mathrm{mg}^{-1}$, respectively. The UV spectra of the obtained laccases were typical for "blue laccases" with a band at $610 \mathrm{~nm}$ for the $\mathrm{T} 1$ copper ion and a shoulder at $340 \mathrm{~nm}$ for the pair of T3 copper ions (Figure S2). Unfortunately, due to its insufficient quantity in the starting material, isozyme Lac7 was lost in the process of purification. 


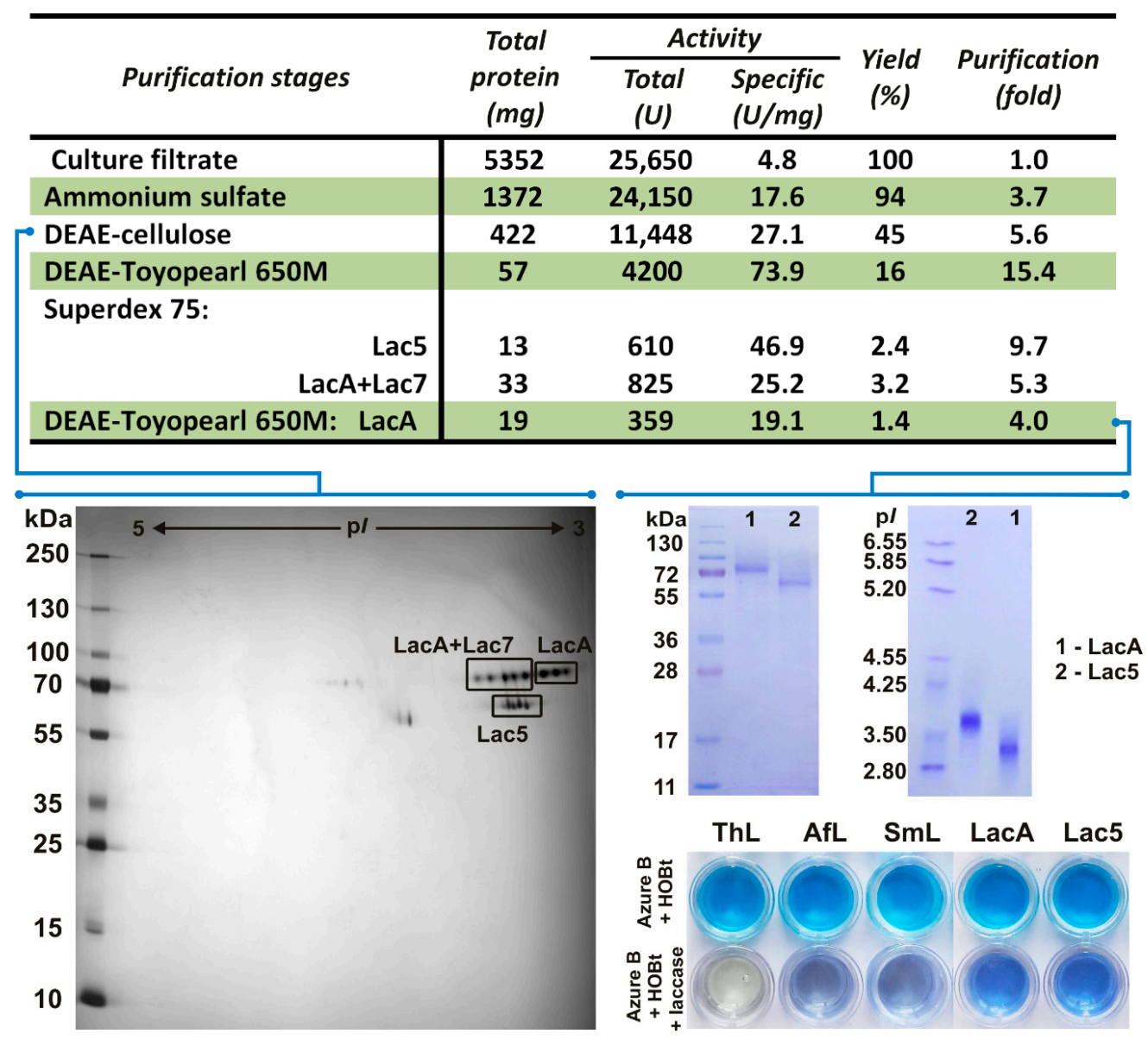

Figure 2. Purification scheme of $P$. lycii laccases and redox potential evaluation for purified Lac5 and LacA using the Azure B decolorization test. ThL-Trametes hirsuta laccase A $\left(E^{0}{ }_{\mathrm{T} 1}=780 \mathrm{mV}\right)$, AfL-Antrodiella faginea laccase A $\left(E^{0} \mathrm{~T} 1=620 \mathrm{mV}\right)$, SmL-Steccherinum murashkinskyi laccase $2\left(E^{0} \mathrm{~T} 1=\right.$ $650 \mathrm{mV})$.

For the purified isozymes Lac5 and LacA, the determined molecular weights were 62 and $74 \mathrm{kDa}$, respectively. Both isozymes were presented by several isoforms with different $\mathrm{pI}$ values. For Lac5, the range of $\mathrm{p} I$ values was 3.7-3.8, while for LacA, this was 3.1-3.3 (Figure 2). As it was previously demonstrated, such values of molecular weight and $\mathrm{pI}$ are typical for laccases of fungi of the Peniophora genus $[20,24,28,29]$ as well as for laccases of basidiomycetes in general [11]. Both laccases were relatively thermostable: the periods of half-life at $70{ }^{\circ} \mathrm{C}$ for Lac 5 and LacA were 10 and $8 \mathrm{~min}$, respectively.

The redox potentials of the obtained laccases were evaluated by the Azure B decolorization test, for which laccases with known redox potentials were used as controls. As it can be seen in Figure 2, LacA of T. hirsuta $(780 \mathrm{mV})$ completely oxidized Azure B within $24 \mathrm{~h}$ in the presence of the HOBt mediator; LacA of A. faginea $(620 \mathrm{mV})$ and Lac2 of S. murashkinskyi $(650 \mathrm{mV})$ demonstrated only partial oxidation of the substrate; and both Lac5 and LacA of P. lycii hardly oxidized Azure B at all. Hence, it can be assumed that the values of the redox potential for both Lac5 and LacA of P. lycii are less than $600 \mathrm{mV}$.

\subsection{Catalytic Activities and Dye Decolorization Capacities of the Obtained Laccases}

Although the broad substrate specificity of laccases is their main advantage, it presents some problems for the unambiguous characterization of these enzymes. Since different studies use different substrates to assess laccase activity, usually, the obtained data are hard to compare with each other. To overcome this problem, in the current study, the panel of the seven most common laccase substrates 
was used: catechol, 2,2-azino-bis(3-ethylbenzothiazoline-6-sulfonic acid) (ABTS), 2,6-dimethoxyphenol (2,6-DMP), guaiacol, gallic acid, sinapic acid, and ferulic acid. The activities were measured at both optimal $\mathrm{pH}$ for the substrate and at $\mathrm{pH} 4.5$.

The results of activity measurements are presented in Table 1 . For all substrates but catechol and ferulic acid, the optimal $\mathrm{pH}$ values for Lac5 were approximately 0.5 units higher than those of LacA. For catechol and ferulic acid, optimal $\mathrm{pH}$ values for Lac5 and LacA were the same. Both isozymes demonstrated the highest activity toward ABTS. While Lac5 demonstrated the lowest activity toward 2,6-DMP, the lowest activity of LacA was detected for gallic acid. The main difference in the activities of Lac5 and LacA was observed for the oxidation of catechol and gallic acid, for which the activity of Lac5 was more than twice higher. Thus, it can be assumed that phenolic compounds with several hydroxyl groups are better substrates for Lac5.

Table 1. The optimal $\mathrm{pH}$ values and catalytic activities of the obtained laccases.

\begin{tabular}{|c|c|c|c|c|c|c|}
\hline \multirow{3}{*}{ Substrate } & \multicolumn{3}{|c|}{ Lac5 } & \multicolumn{3}{|c|}{ LacA } \\
\hline & \multirow{2}{*}{ Optimal pH } & \multicolumn{2}{|c|}{ Activity $^{*}, \mathrm{U} \cdot \mathrm{mg}^{-1}$} & \multirow{2}{*}{ Optimal pH } & \multicolumn{2}{|c|}{ Activity, U.mg ${ }^{-1}$} \\
\hline & & Optimal pH & pH 4.5 & & Optimal pH & pH 4.5 \\
\hline Catechol & $4.0-4.5$ & 46.8 & 46.8 & $4.0-4.5$ & 19.1 & 19.1 \\
\hline ABTS & 3 & 96.9 & 36.8 & $<2.5$ & 121.4 & 9.2 \\
\hline 2,6-DMP & $3.5-4.5$ & 2.5 & 2.5 & 3.5 & 2.5 & 1.7 \\
\hline Guaiacol & $3.5-4.0$ & 3.8 & 2.9 & $3.0-3.5$ & 3.6 & 2.3 \\
\hline Sinapic acid & $3.5-4.0$ & 11.2 & 9.1 & $3.0-3.5$ & 8.0 & 6.2 \\
\hline Ferulic acid & $3.5-4.0$ & 3.1 & 2.6 & $3.5-4.0$ & 4.1 & 3.1 \\
\hline Gallic acid & 4.0 & 4.1 & 3.2 & 4.5 & 1.4 & 1.4 \\
\hline
\end{tabular}

${ }^{*} \pm \mathrm{SD}$ did not exceed $5 \%$ of the given values. When not a single $\mathrm{pH}$ value but rather a range of $\mathrm{pH}$ values was optimal, the mean value of the range was used for activity measurement.

It should be noted that the obtained Lac5 isozyme had similar physicochemical and catalytic properties with the previously characterized laccase from Peniophora sp. VTT D-00815 [28], belonging to the same fifth orthology group. This laccase was also presented by several isoforms with a $\mathrm{pI}$ range of 3.7-4.2 and a molecular weight of $63 \mathrm{kDa}$. The period of half-life at $70{ }^{\circ} \mathrm{C}$ was $15 \mathrm{~min}$, and the specific activity towards guaiacol and DMP was $12 \%$ of that towards ABTS. At the same time, both Lac5 and LacA were markedly different from the previously characterized Lac1 from Peniophora sp. CBMAI [22], belonging to the 18th orthology group. This laccase had a lower molecular weight of $55 \mathrm{kDa}$, approximately 10 times higher specific activity towards ABTS $\left(986.0 \mathrm{U} \cdot \mathrm{mg}^{-1}\right.$ ), and lower thermal stability $\left(20\right.$ min half-life at $\left.60^{\circ} \mathrm{C}\right)$.

Currently, one of the most straightforward technical applications of laccases is decolorization of different textile dyes [59]. Being released in enormous quantities by the textile dyeing and finishing industry, textile dyes substantially contribute to the pollution of surface and groundwater resources [18]. Moreover, many synthetic dyes can act as toxic, mutagenic, allergenic, and carcinogenic agents [60]. Although synthetic dyes are very chemically heterogenic, many of them contain functional groups suitable for laccase oxidation [61].

The dye-removing capacity of the obtained laccase isozymes was assessed using a panel of six dyes: the anthraquinone dye Remazol Brilliant Blue R (RBBR), the triphenylmethane dye Bromocresol Green (BCG), the sulfonic acid dye Phenol Red (PR), the azo dye Reactive Black 5 (RB5), the indigoid dye Indigo Carmine (IC), and the diazo dye Congo Red (CR).

As it is shown in Figure 3, both Lac5 and LacA demonstrated near identical dye-removing capacity. Within 24 hours' time, these isozymes almost entirely decolorized such dyes as BCG and RBBR. The dyes IC, PR, and CR were decolorized only by approximately 35,15 , and $10 \%$. In the case of RB5, there was no decolorization detected. 

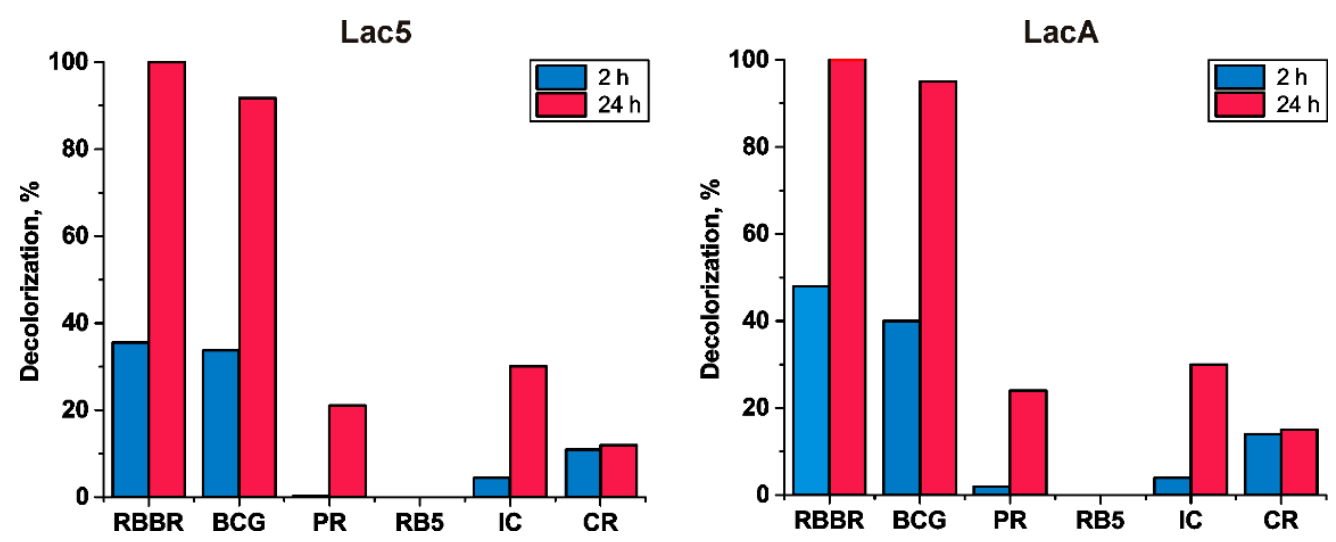

Figure 3. Decolorization of different dyes by P. lycii laccases. RBBR-Remazol Brilliant Blue R, BCG—Bromocresol Green, PR-Phenol Red, RB5-Reactive Black 5, IC—Indigo Carmine, CR-Congo Red.

\subsection{Identification of Primary Amino Acid Sequences and Structural Features of the Obtained Laccases}

As it was mentioned, the primary sequence of LacA was already determined in our previous works $[13,54]$. To determine the primary sequence of Lac5, the specific primers were designed based on the alignment of the laccase sequences from the fifth orthology group (Figure 1). As a result, the lac5 gene was successfully amplified and sequenced, its exon-intron structure was determined, and the coding region was conceptually translated. The obtained sequence was deposited into Gene Bank under the accession number MW172826.

The amino acid sequences of both Lac5 and LacA contained specific laccase signature regions L1-L4 (Kumar 2003) (Figure 4). These regions contain copper coordinating residues of the laccase active site. In both laccases, one cysteine and ten histidine residues were found which confirm that the obtained enzymes can act as the classical laccase with four copper ions in its active site. Further analysis of the Lac5 and LacA amino acid sequences revealed the presence of six and seven potential $\mathrm{N}$-glycosylation sites (N-X-T/S motif), respectively (Figure 4). To reveal the actually glycosylated asparagine residues, samples of native laccases and laccases treated with Endo $\mathrm{H}$ were subjected to MALDI TOF/TOF mass spectrometry analysis. Deglycosylation with Endo H resulted in a decrease in molecular mass of $8 \%$ for both Lac5 and LacA. Only two sites for each laccase were confirmed to be glycosylated (Figure 4). Lac5 and LacA enzymes have the same N-glycosylated site at Asn421 (according to the LacA sequence without a signal peptide). Other occupied sites were Asn300 for Lac5 and Asn267 for LacA. Among the previously characterized laccases, modified Asn 421 was found only in laccases from fungi of the Steccherinaceae family-A. faginea (PDB 5EHF), S. murashkinskyi (PDB 5E9N) and S. ochraceum (PDB 3T6W [62])—while modified Asn267 and Asn300 have never been observed in other basidiomycete laccases.

The oxidation of the substrate takes place at the $\mathrm{T} 1$ copper center of laccase [63]. Laccase catalytic activity significantly depends on the T1 copper center redox potential and also on the structure of the loops near the T1 copper center which form the substrate binding pocket $[34,64,65]$. To reveal the structural features of the potential substrate binding pocket of $P$. lycii laccases, homology-based modeling was performed. For both Lac5 and LacA, the high-resolution structure of S. murashkinskyi laccase (PDB 5E9N) was used as a template. GMQE scores were 0.83 for the Lac5 model and 0.82 for the LacA model which indicate a generally high quality of the predicted structures. It should be noted that the substrate binding pocket of laccase is formed by conservative regions (S2, S3, and S7 in Figure 5) and also by variable flexible loops (S1, S4-S6 in Figure 5) near the T1 copper center. Therefore, the obtained models could be used only for the mapping of amino acid residues potentially forming the substrate binding pocket of $P$. lycii laccases on the 3D structure of the enzyme, but the actual positions of the variable loops may differ. 
Previously, it was shown that the type of amino acid residue located near the T1 copper ion (corresponding to Leu471 in LacA P. lycii laccase, blue color in Figure 5) may affect the value of its redox potential $[66,67]$. High-redox potential basidiomycete laccases $\left(E^{0} \mathrm{T1}>700 \mathrm{mV}\right)$ almost always have Phe residue in this position, while in middle-redox potential laccases $\left(550 \mathrm{mV}<E^{0} \mathrm{~T} 1<700 \mathrm{mV}\right.$ ), Leu residue is more common [68]. Further, the value of the laccase redox potential is correlated with the structure of the variable loops near the T1 copper center [34]. Both P. lycii laccases have a shorter S6 loop as in all middle-redox potential laccases with known structures [34]. These findings are in agreement with the results of the Azure B test and the hypothesis that Lac5 and LacA from P. lycii have a middle redox potential below $600 \mathrm{mV}$.

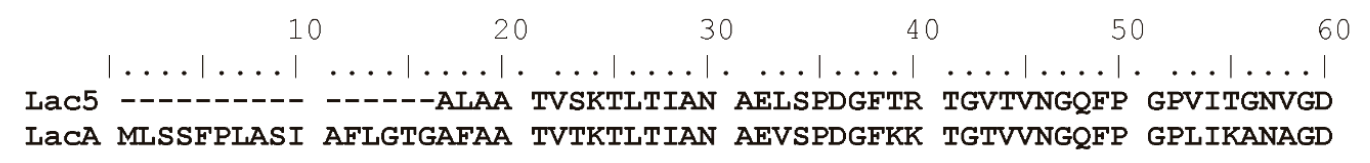

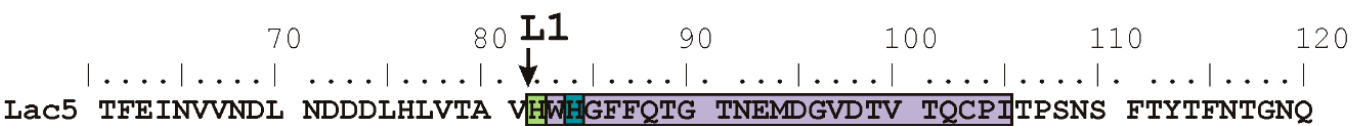 LACA DFEITVADDL KDESLALVTS H蓷GFFQKG TNEMDGVATV TQCPITPGNE FTYKFSSANQ

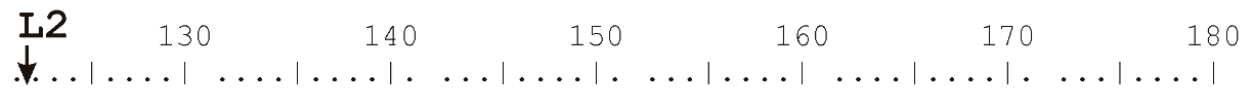

LaC5 AGTYWY ISE Y KTQYCDGLRG AIVVYDPNDP HKSLYDVDDE STIITLGDWY HFNSPQAPII LACA A GTYWYHSHY STQYCDGLRG PIVVYDPHDP HKSLYDVDDE STVITLADWY HFPSTQAPAI

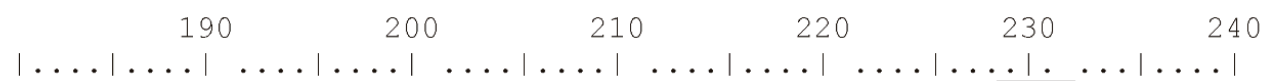

LAC5 VFINSTIING KGRYIDEFGS NLTNELAVVN VKAGTKYRMR VISVSCD NNY TFSIDKHQMT LACA VNINSTIING LGRYNDPIGS DLTQPLAVVN VVKGTRYRMR LVSILCDPNF IFSIDQHQMT

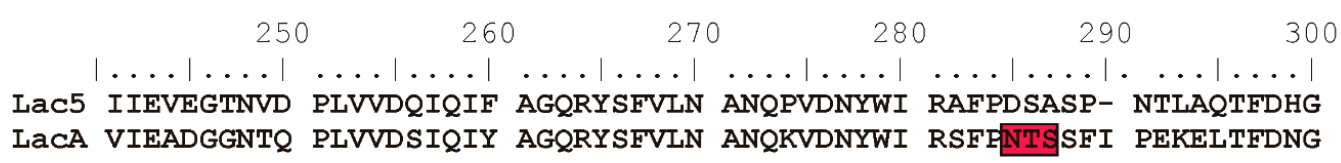

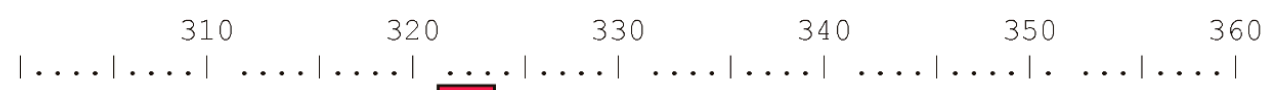

LaC5 LNQAILRYSG APSSDP-TTT NSSTLPLLET NLHPLTPAPV PGTHKAGGAD QTLTLNIEFD LACA LNSAILRYKG AKIAEPTTPN KPSVQPLVET NLHPLVPTPP PQGPADKTLN LQIALDIDLA

$$
\begin{array}{|c|c|c|c|c|c|c|}
370 & 380 & 390 & 400 & 410 & 420
\end{array}
$$

LAC5 PTTTGFAVNN VPYTAPSVPI LLQILSGNTS AQELLPKGSI YELQPNTVVD IVMPGGSRGG LACA DNTGVFTINN ATYTPPKFPV LLQILSGNTS AQSLVPEHSI YELEHNTIVD LVIPGGSLGG
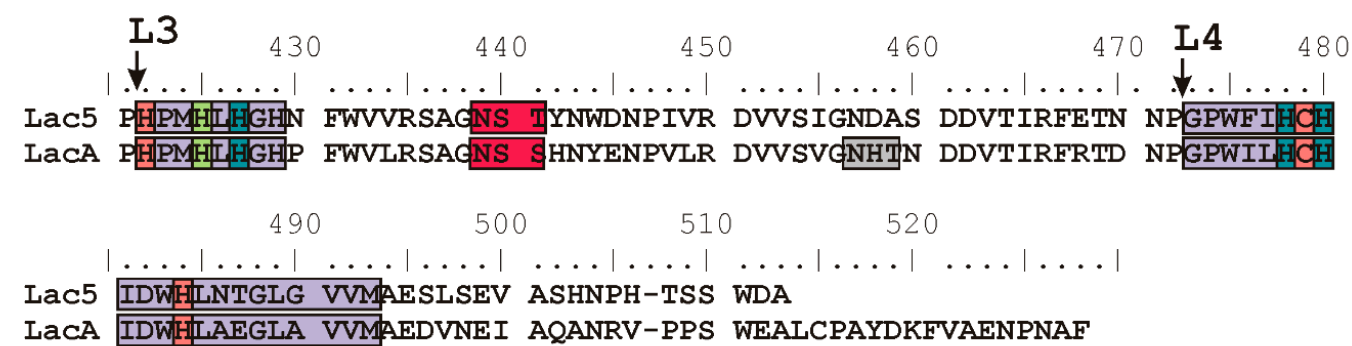

Figure 4. Alignment of the amino acid sequences of Lac5 and LacA from P. lycii. Laccase signature regions L1-L4 (according to [69]) are indicated with violet. Copper coordinating amino acid residues are indicated with coral for the T1 copper ion, leaf green for the T2 copper ion, and marine blue for the pair of T3 copper ions. Potential glycosylation sites are colored with gray and occupied glycosylation sites are colored with red. 


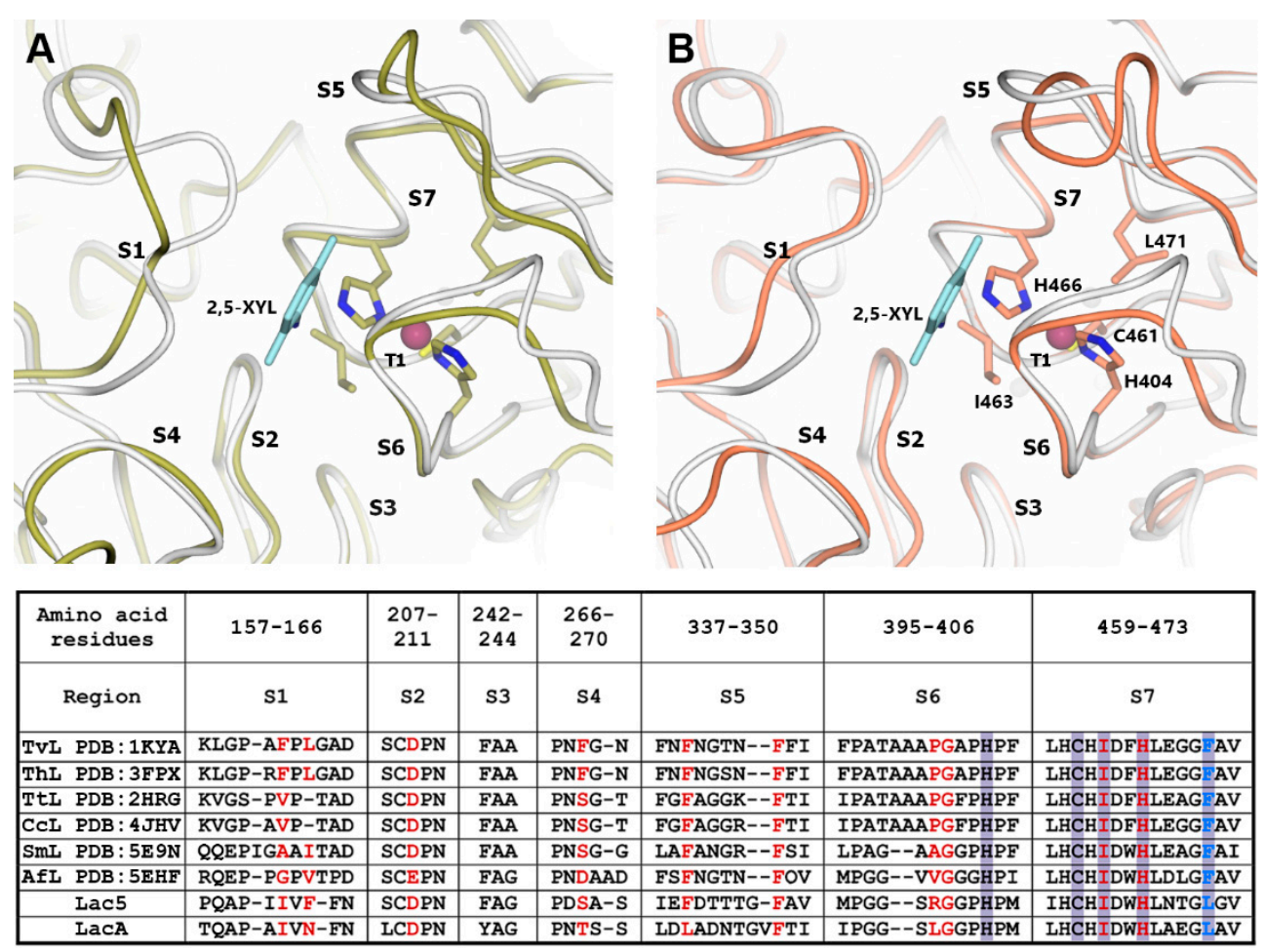

Figure 5. Three-dimensional models of $\mathrm{T} 1$ active sites and their surroundings for Lac5 (A, yellow) and LacA (B, coral). Model of T. versicolor laccase complexed with 2,5-xylidine (PDB 1KYA, [70]) is shown in white. Copper ions are indicated as purple spheres. Side chains of the amino acid residues from the primary coordination sphere of the T1 copper ion are shown as stick models. Molecule of 2,5-xylidine is shown with light blue color. Alignment of the amino acid sequences of regions near the $\mathrm{T} 1$ active sites for laccases from T. versicolor (TvL), T. hirsuta (ThL), T. trogii (TtL), Coriolopsis caperata (CcL), S. murashkinskyi (SmL), and A. faginea (AfL) and P. lycii laccases Lac5 and LacA is presented in the table. Amino acid residues forming the substrate binding pocket identified according to the structures of T. versicolor laccase complexed with 2,5-xylidine and T. trogii laccase complexed with p-toluate [71] are shown with red. Violet color indicates the residues from the primary coordination sphere of the T1 copper ion. Blue color indicates non-conservative residue from the primary coordination sphere of the T1 copper ion. Amino acid numbering corresponds to the LacA sequence without the signal peptide.

Another interesting feature of the LacA structure is the presence of an occupied glycosylation site (Asn267) in the S4 loop. The branched carbohydrate chain attached to Asn267 may significantly affect the binding mode of the substrate as the next residue in the polypeptide chain participates in the interaction with the substrate [70]. The presence of the occupied glycosylation site at Asn267 could be the possible reason for the lower activity of LacA toward almost all substrates compared to Lac5.

\section{Conclusions}

In this work, two novel laccases of P. lycii-Lac5 and LacA-were purified and characterized. The molecular weights of purified isozymes Lac5 and LacA were 62 and $74 \mathrm{kDa}$ and the $\mathrm{p} I$ values were 3.7-3.8 and 3.1-3.3, respectively. Both laccases demonstrated good thermostability with periods of half-life at $70{ }^{\circ} \mathrm{C}$ of 10 and $8 \mathrm{~min}$ for Lac5 and LacA, respectively. For all substrates but catechol and ferulic acid, the optimal $\mathrm{pH}$ values for Lac5 were approximately 0.5 units higher than those of LacA. Both laccases demonstrated the highest activity toward ABTS $\left(97 \mathrm{U} \cdot \mathrm{mg}^{-1}\right.$ for Lac5 and $121 \mathrm{U} \cdot \mathrm{mg}^{-1}$ for LacA at $\mathrm{pH} 4.5)$. Lac5 demonstrated the lowest activity toward 2,6-DMP (2.5 U.mg ${ }^{-1}$ at $\left.\mathrm{pH} 4.5\right)$, while LacA demonstrated this towards gallic acid $\left(1.4 \mathrm{U} \cdot \mathrm{mg}^{-1}\right.$ at $\left.\mathrm{pH} 4.5\right)$. Since the activity of Lac5 by catechol (46.8 $\mathrm{U} \cdot \mathrm{mg}^{-1}$ at $\left.\mathrm{pH} 4.5\right)$ and gallic acid (3.2 $\mathrm{U} \cdot \mathrm{mg}^{-1}$ at $\mathrm{pH}$ 4.5) was more than twice higher than that of LacA (19.1 and $1.4 \mathrm{U} \cdot \mathrm{mg}^{-1}$ at $\mathrm{pH} 4.5$, respectively), it can be assumed that phenolic compounds 
with several hydroxyl groups are better substrates for Lac5. Both laccases demonstrated near identical dye-removing capacity: within 24 hours' time, they almost entirely decolorized BCG and RBBR; IC, PR, and CR were decolorized only by approximately 35,15 , and $10 \%$; and for RB5, no decolorization was detected. The nucleotide sequences of Lac5 (GenBank MW172826) and LacA (GenBank MG550090) were determined, the corresponding amino acid sequences were deduced, and structural modeling was performed. Both laccases demonstrated structural features typical for middle-redox potential laccases. Additionally, glycosylation patterns of laccases were determined using MALDI-TOF-TOF-MS/MS. It was proposed that the presence of the Asn267-occupied glycosylation site in LacA could be the reason for the lower activity of this laccase toward almost all substrates compared to Lac5.

Supplementary Materials: The following are available online at http://www.mdpi.com/2309-608X/6/4/340/ s1, Figure S1: Identified peptides in P. lycii laccase samples. Figure S2: Laccase UV-vis spectra, File S1: Full_Alignment.aln, File S2: Trimmed_Alignment.aln.

Author Contributions: Conceptualization, T.V.F., O.A.G., and K.V.M.; formal analysis, O.A.G., K.V.M., O.S.S., and T.V.F.; investigation, O.A.G., K.V.M., O.S.S., and T.V.F.; data curation, T.V.F.; writing-original draft preparation, O.A.G.; writing-review and editing, O.A.G., K.V.M., O.S.S., and T.V.F.; visualization, O.A.G. and K.V.M.; supervision, T.V.F. All authors have read and agreed to the published version of the manuscript.

Funding: This work was partially supported by the Russian Foundation for Basic Research (RFBR) (Grant No. 19-04-01183).

Acknowledgments: Authors would like to thank N.V. Psurtseva for providing the P. lycii strain. The MALDI mass spectrometry was carried out on equipment of the Shared-Access Equipment Centre "Industrial Biotechnology" of Federal Research Center "Fundamentals of Biotechnology" of the Russian Academy of Sciences.

Conflicts of Interest: The authors declare no conflict of interest.

\section{References}

1. Lonsdale, D.; Pautasso, M.; Holdenrieder, O. Wood-decaying fungi in the forest: Conservation needs and management options. Eur. J. For. Res. 2008, 127, 1-22. [CrossRef]

2. Marcot, B.G. A review of the role of fungi in wood decay of forest ecosystems. USDA Res. Note. PNW-RN-575 2017, 1-31.

3. Giardina, P.; Faraco, V.; Pezzella, C.; Piscitelli, A.; Vanhulle, S.; Sannia, G. Laccases: A never-ending story. Cell. Mol. Life Sci. 2010, 67, 369-385. [CrossRef]

4. Pezzella, C.; Guarino, L.; Piscitelli, A. How to enjoy laccases. Cell. Mol. Life Sci. 2015, 72, 923-940. [CrossRef] [PubMed]

5. Yang, J.; Li, W.; Ng, T.B.; Deng, X.; Lin, J.; Ye, X. Laccases: Production, expression regulation, and applications in pharmaceutical biodegradation. Front. Microbiol. 2017, 8, 832. [CrossRef] [PubMed]

6. Mate, D.M.; Alcalde, M. Laccase: A multi-purpose biocatalyst at the forefront of biotechnology. Microb. Biotechnol. 2017, 10, 1457-1467. [CrossRef] [PubMed]

7. Riva, S. Laccases: Blue enzymes for green chemistry. Trends Biotechnol. 2006, 24, 219-226. [CrossRef]

8. Rodríguez Couto, S.; Toca Herrera, J.L. Industrial and biotechnological applications of laccases: A review. Biotechnol. Adv. 2006, 24, 500-513. [CrossRef]

9. Mayer, A.M.; Staples, R.C. Laccase: New functions for an old enzyme. Phytochemistry 2002, 60, 551-565. [CrossRef]

10. Janusz, G.; Pawlik, A.; Świderska-Burek, U.; Polak, J.; Sulej, J.; Jarosz-Wilkołazka, A.; Paszczyński, A. Laccase Properties, Physiological Functions, and Evolution. Int. J. Mol. Sci. 2020, 21, 966. [CrossRef]

11. Baldrian, P. Fungal laccases-occurrence and properties. FEMS Microbiol. Rev. 2006, 30, 215-242. [CrossRef] [PubMed]

12. Grigoriev, I.V.; Nikitin, R.; Haridas, S.; Kuo, A.; Ohm, R.; Otillar, R.; Riley, R.; Salamov, A.; Zhao, X.; Korzeniewski, F.; et al. MycoCosm portal: Gearing up for 1000 fungal genomes. Nucleic Acids Res. 2014, 42, D699-D704. [CrossRef] [PubMed]

13. Savinova, O.S.; Moiseenko, K.V.; Vavilova, E.A.; Chulkin, A.M.; Fedorova, T.V.; Tyazhelova, T.V.; Vasina, D.V.; Moiseenko, K.V.; Chulkin, A.M.; Vasina, D.V.; et al. Evolutionary Relationships Between the Laccase Genes of Polyporales: Orthology-Based Classification of Laccase Isozymes and Functional Insight from Trametes hirsuta. Front. Microbiol. 2019, 10, 1-14. [CrossRef] [PubMed] 
14. Altenhoff, A.M.; Studer, R.A.; Robinson-Rechavi, M.; Dessimoz, C. Resolving the Ortholog Conjecture: Orthologs Tend to Be Weakly, but Significantly, More Similar in Function than Paralogs. PLoS Comput. Biol. 2012, 8, e1002514. [CrossRef]

15. Chen, X.; Zhang, J. The Ortholog Conjecture Is Untestable by the Current Gene Ontology but Is Supported by RNA Sequencing Data. PLoS Comput. Biol. 2012, 8, e1002784. [CrossRef]

16. Gabaldón, T.; Koonin, E.V. Functional and evolutionary implications of gene orthology. Nat. Rev. Genet. 2013, 14, 360-366. [CrossRef]

17. Miller, S.L.; Larsson, E.; Larsson, K.-H.; Verbeken, A.; Nuytinck, J. Perspectives in the new Russulales. Mycologia 2006, 98, 960-970. [CrossRef]

18. Poojary, H.; Hoskeri, A.; Kaur, A.; Mugeraya, G. Comparative production of ligninolytic enzymes from novel isolates of Basidiomycetes and their potential to degrade textile dyes. Nat. Sci. 2012, 10, 90-96.

19. Bonugli-Santos, R.C.; Vieira, G.A.L.; Collins, C.; Fernandes, T.C.C.; Marin-Morales, M.A.; Murray, P.; Sette, L.D. Enhanced textile dye decolorization by marine-derived basidiomycete Peniophora sp. CBMAI 1063 using integrated statistical design. Environ. Sci. Pollut. Res. 2016, 23, 8659-8668. [CrossRef]

20. Moreira, S.; Milagres, A.M.F.; Mussatto, S.I. Reactive dyes and textile effluent decolorization by a mediator system of salt-tolerant laccase from Peniophora cinerea. Sep. Purif. Technol. 2014, 135, 183-189. [CrossRef]

21. Majul, L.; Wirth, S.; Levin, L. High dye removal capacity of Peniophora laxitexta immobilized in a combined support based on polyurethane foam and lignocellulosic substrates. Environ. Technol. 2020, 1-12. [CrossRef] [PubMed]

22. Mainardi, P.H.; Feitosa, V.A.; Brenelli de Paiva, L.B.; Bonugli-Santos, R.C.; Squina, F.M.; Pessoa, A.; Sette, L.D. Laccase production in bioreactor scale under saline condition by the marine-derived basidiomycete Peniophora sp. CBMAI 1063. Fungal Biol. 2018, 122, 302-309. [CrossRef] [PubMed]

23. Alberts, J.F.; Gelderblom, W.C.A.; Botha, A.; van Zyl, W.H. Degradation of aflatoxin B1 by fungal laccase enzymes. Int. J. Food Microbiol. 2009, 135, 47-52. [CrossRef] [PubMed]

24. Son, M.-J.; Kim, Y.-H.; Nam, S.-W.; Jeon, S.-J. Optimization of Media Composition on the Production of Melanin Bleaching Enzyme from Peniophora sp. JS17. Microbiol. Biotechnol. Lett. 2019, 47, 250-258. [CrossRef]

25. Lee, H.; Jang, Y.; Lee, Y.M.; Lee, H.; Kim, G.H.; Kim, J.J. Enhanced removal of PAHs by Peniophora incarnata and ascertainment of its novel ligninolytic enzyme genes. J. Environ. Manag. 2015, 164, 10-18. [CrossRef]

26. Silvério, S.C.; Moreira, S.; Milagres, A.M.F.; Macedo, E.A.; Teixeira, J.A.; Mussatto, S.I. Laccase production by free and immobilized mycelia of Peniophora cinerea and Trametes versicolor: A comparative study. Bioprocess Biosyst. Eng. 2013, 36, 365-373. [CrossRef]

27. Shankar, S. Shikha Laccase production and enzymatic modification of lignin by a novel Peniophora sp. Appl. Biochem. Biotechnol. 2012, 166, 1082-1094. [CrossRef]

28. Niku-Paavola, M.-L.; Fagerström, R.; Kruus, K.; Viikari, L. Thermostable laccases produced by a white-rot fungus from Peniophora species. Enzyme Microb. Technol. 2004, 35, 100-102. [CrossRef]

29. Brenelli, L.B.; Persinoti, G.F.; Cairo, J.P.L.F.; Liberato, M.V.; Gonçalves, T.A.; Otero, I.V.R.; Mainardi, P.H.; Felby, C.; Sette, L.D.; Squina, F.M. Novel redox-active enzymes for ligninolytic applications revealed from multiomics analyses of Peniophora sp. CBMAI 1063, a laccase hyper-producer strain. Sci. Rep. 2019, 9, 17564. [CrossRef]

30. Koroljova-Skorobogat'ko, O.V.; Stepanova, E.V.; Gavrilova, V.P.; Morozova, O.V.; Lubimova, N.V.; Dzchafarova, A.N.; Jaropolov, A.I.; Makower, A. Purification and characterization of the constitutive form of laccase from the basidiomycete Coriolus hirsutus and effect of inducers on laccase synthesis. Biotechnol. Appl. Biochem. 1998, 28 Pt 1, 47-54.

31. Laemmli, U. Relevant page on gel electrophoresis. Nature 1970, 227, 681.

32. Glazunova, O.A.; Moiseenko, K.V.; Kamenihina, I.A.; Isaykina, T.U.; Yaropolov, A.I.; Fedorova, T.V. Laccases with variable properties from different strains of Steccherinum ochraceum: Does glycosylation matter? Int. J. Mol. Sci. 2019, 20, 2008. [CrossRef] [PubMed]

33. Glazunova, O.A.; Shakhova, N.V.; Psurtseva, N.V.; Moiseenko, K.V.; Kleimenov, S.Y.; Fedorova, T.V.; Moiseenko, K.V.; Kleimenov, S.Y.; Fedorova, T.V. White-rot basidiomycetes Junghuhnia nitida and Steccherinum bourdotii: Oxidative potential and laccase properties in comparison with Trametes hirsuta and Coriolopsis caperata. PLoS ONE 2018, 13, 1-22. [CrossRef] [PubMed] 
34. Glazunova, O.A.; Polyakov, K.M.; Moiseenko, K.V.; Kurzeev, S.A.; Fedorova, T.V. Structure-function study of two new middle-redox potential laccases from basidiomycetes Antrodiella faginea and Steccherinum murashkinskyi. Int. J. Biol. Macromol. 2018, 118, 406-418. [CrossRef] [PubMed]

35. Koroleva, O.V.; Yavmetdinov, I.S.; Shleev, S.V.; Stepanova, E.V.; Gavrilova, V.P. Isolation and study of some properties of laccase from the basidiomycete Cerrena maxima. Biochemistry 2001, 66, 618-622. [CrossRef]

36. Park, K.M.; Park, S.-S. Purification and characterization of laccase from basidiomycete Fomitella fraxinea. J. Microbiol. Biotechnol. 2008, 18, 670-675. [PubMed]

37. DePillis, G.D.; Sishta, B.P.; Mauk, A.G.; Ortiz de Montellano, P.R. Small substrates and cytochrome c are oxidized at different sites of cytochrome c peroxidase. J. Biol. Chem. 1991, 266, 19334-19341.

38. Rodríguez-Rincón, F.; Suarez, A.; Lucas, M.; Larrondo, L.F.; De La Rubia, T.; Polaina, J.; Martínez, J. Molecular and structural modeling of the Phanerochaete flavido-alba extracellular laccase reveals its ferroxidase structure. Arch. Microbiol. 2010, 192, 883-892. [CrossRef]

39. Glazunova, O.A.; Trushkin, N.A.; Moiseenko, K.V.; Filimonov, I.S.; Fedorova, T.V. Catalytic efficiency of basidiomycete laccases: Redox potential versus substrate-binding pocket structure. Catalysts 2018, 8, 152. [CrossRef]

40. Stanke, M.; Steinkamp, R.; Waack, S.; Morgenstern, B. AUGUSTUS: A web server for gene finding in eukaryotes. Nucleic Acids Res. 2004, 32, W309-W312. [CrossRef]

41. Nordberg, H.; Cantor, M.; Dusheyko, S.; Hua, S.; Poliakov, A.; Shabalov, I.; Smirnova, T.; Grigoriev, I.V.; Dubchak, I. The genome portal of the Department of Energy Joint Genome Institute: 2014 updates. Nucleic Acids Res. 2014, 42, D26-D31. [CrossRef] [PubMed]

42. Clark, K.; Karsch-Mizrachi, I.; Lipman, D.J.; Ostell, J.; Sayers, E.W. GenBank. Nucleic Acids Res. 2016, 44, D67-D72. [CrossRef] [PubMed]

43. Altschul, S.F.; Gish, W.; Miller, W.; Myers, E.W.; Lipman, D.J. Basic local alignment search tool. J. Mol. Biol. 1990, 215, 403-410. [CrossRef]

44. Edgar, R.C. MUSCLE: Multiple sequence alignment with high accuracy and high throughput. Nucleic Acids Res. 2004, 32, 1792-1797. [CrossRef] [PubMed]

45. Larsson, A. AliView: A fast and lightweight alignment viewer and editor for large datasets. Bioinformatics 2014, 30, 3276-3278. [CrossRef]

46. Castresana, J. Selection of conserved blocks from multiple alignments for their use in phylogenetic analysis. Mol. Biol. Evol. 2000, 17, 540-552. [CrossRef]

47. Darriba, D.; Taboada, G.L.; Doallo, R.; Posada, D. jModelTest 2: More models, new heuristics and parallel computing. Nat. Methods 2012, 9, 772. [CrossRef]

48. Stamatakis, A. RAxML version 8: A tool for phylogenetic analysis and post-analysis of large phylogenies. Bioinformatics 2014, 30, 1312-1313. [CrossRef]

49. Miller, M.A.; Pfeiffer, W.; Schwartz, T. Creating the CIPRES Science Gateway for inference of large phylogenetic trees. In 2010 Gateway Computing Environments Workshop (GCE); IEEE: Piscataway, NJ, USA, 2010; pp. 1-8.

50. Almagro Armenteros, J.J.; Tsirigos, K.D.; Sønderby, C.K.; Petersen, T.N.; Winther, O.; Brunak, S.; von Heijne, G.; Nielsen, H. SignalP 5.0 improves signal peptide predictions using deep neural networks. Nat. Biotechnol. 2019, 37, 420-423. [CrossRef]

51. Gupta, R.; Jung, E.; Brunak, S. Prediction of N-Glycosylation Sites in Human Proteins. Available online: http://www.cbs.dtu.dk/services2002 (accessed on 5 November 2020).

52. Waterhouse, A.; Bertoni, M.; Bienert, S.; Studer, G.; Tauriello, G.; Gumienny, R.; Heer, F.T.; de Beer, T.A.P.; Rempfer, C.; Bordoli, L.; et al. SWISS-MODEL: Homology modelling of protein structures and complexes. Nucleic Acids Res. 2018, 46, W296-W303. [CrossRef]

53. McNicholas, S.; Potterton, E.; Wilson, K.S.; Noble, M.E.M. Presenting your structures: The CCP4mg molecular-graphics software. Acta Crystallogr. Sect. D Biol. Crystallogr. 2011, 67, 386-394. [CrossRef] [PubMed]

54. Moiseenko, K.V.; Maloshenok, L.G.; Vasina, D.V.; Bruskin, S.A.; Tyazhelova, T.V.; Koroleva, O.V. Laccase multigene families in Agaricomycetes. J. Basic Microbiol. 2016, 1-6. [CrossRef] [PubMed]

55. Moiseenko, K.V.; Glazunova, O.A.; Shakhova, N.V.; Savinova, O.S.; Vasina, D.V.; Tyazhelova, T.V.; Psurtseva, N.V.; Fedorova, T.V. Fungal adaptation to the advanced stages of wood decomposition: Insights from the Steccherinum ochraceum. Microorganisms 2019, 7, 527. [CrossRef] [PubMed] 
56. Hoegger, P.J.; Kilaru, S.; James, T.Y.; Thacker, J.R.; Kües, U. Phylogenetic comparison and classification of laccase and related multicopper oxidase protein sequences. FEBS J. 2006, 273, 2308-2326. [CrossRef]

57. Kues, U.; Ruhl, M. Multiple multi-copper oxidase gene families in Basidiomycetes-What for? Curr. Genomics 2011, 12, 72-94. [CrossRef]

58. Otero, I.V.R.; Ferro, M.; Bacci, M.; Ferreira, H.; Sette, L.D. De novo transcriptome assembly: A new laccase multigene family from the marine-derived basidiomycete Peniophora sp. CBMAI 1063. AMB Express 2017, 7, 222. [CrossRef]

59. Mishra, A.; Kumar, S.; Bhatnagar, A. Potential of Fungal Laccase in Decolorization of Synthetic Dyes. In Microbial Wastewater Treatment; Elsevier: Amsterdam, The Netherlands, 2019; pp. 127-151.

60. Lellis, B.; Fávaro-Polonio, C.Z.; Pamphile, J.A.; Polonio, J.C. Effects of textile dyes on health and the environment and bioremediation potential of living organisms. Biotechnol. Res. Innov. 2019, 3, $275-290$. [CrossRef]

61. Legerská, B.; Chmelová, D.; Ondrejovič, M. Degradation of Synthetic Dyes by Laccases—A Mini-Review. Nov. Biotechnol. Chim. 2016, 15,90-106. [CrossRef]

62. Ferraroni, M.; Matera, I.; Chernykh, A.; Kolomytseva, M.; Golovleva, L.A.; Scozzafava, A.; Briganti, F. Reaction intermediates and redox state changes in a blue laccase from Steccherinum ochraceum observed by crystallographic high/low X-ray dose experiments. J. Inorg. Biochem. 2012, 111, 203-209. [CrossRef]

63. Solomon, E.I.; Sundaram, U.M.; Machonkin, T.E. Multicopper oxidases and oxygenases. Chem. Rev. 1996, 96, 2563-2606. [CrossRef]

64. Frasconi, M.; Favero, G.; Boer, H.; Koivula, A.; Mazzei, F. Kinetic and biochemical properties of high and low redox potential laccases from fungal and plant origin. Biochim. Biophys. Acta 2010, 1804, 899-908. [CrossRef] [PubMed]

65. $\mathrm{Xu}, \mathrm{F}$. Oxidation of phenols, anilines, and benzenethiols by fungal laccases: Correlation between activity and redox potentials as well as halide inhibition. Biochemistry 1996, 35, 7608-7614. [CrossRef] [PubMed]

66. Xu, F.; Berka, R.M.; Wahleithner, J.; Nelson, B. Site-directed mutations in fungal laccase: Effect on redox potential, activity and $\mathrm{pH}$ profile. Biochem. J. 1998, 70, 63-70. [CrossRef] [PubMed]

67. Osipov, E.; Polyakov, K.; Kittl, R.; Shleev, S.; Dorovatovsky, P.; Tikhonova, T.; Hann, S.; Ludwig, R.; Popov, V. Effect of the L499M mutation of the ascomycetous Botrytis aclada laccase on redox potential and catalytic properties. Acta Crystallogr. Sect. D Biol. Crystallogr. 2014, 70, 2913-2923. [CrossRef]

68. Rodgers, C.J.; Blanford, C.F.; Giddens, S.R.; Skamnioti, P.; Armstrong, F.A.; Gurr, S.J. Designer laccases: A vogue for high-potential fungal enzymes? Trends Biotechnol. 2010, 28, 63-72. [CrossRef]

69. Kumar, S.V.S.; Phale, P.S.; Durani, S.; Wangikar, P.P. Combined sequence and structure analysis of the fungal laccase family. Biotechnol. Bioeng. 2003, 83, 386-394. [CrossRef]

70. Bertrand, T.; Jolivalt, C.; Briozzo, P.; Caminade, E.; Joly, N.; Madzak, C.; Mougin, C. Crystal structure of a four-copper laccase complexed with an arylamine: Insights into substrate recognition and correlation with kinetics. Biochemistry 2002, 41, 7325-7333. [CrossRef]

71. Matera, I.; Gullotto, A.; Tilli, S.; Ferraroni, M.; Scozzafava, A.; Briganti, F. Crystal structure of the blue multicopper oxidase from the white-rot fungus Trametes trogii complexed with p-toluate. Inorganica Chim. Acta 2008, 361, 4129-4137. [CrossRef]

Publisher's Note: MDPI stays neutral with regard to jurisdictional claims in published maps and institutional affiliations.

(C) 2020 by the authors. Licensee MDPI, Basel, Switzerland. This article is an open access article distributed under the terms and conditions of the Creative Commons Attribution (CC BY) license (http://creativecommons.org/licenses/by/4.0/). 